
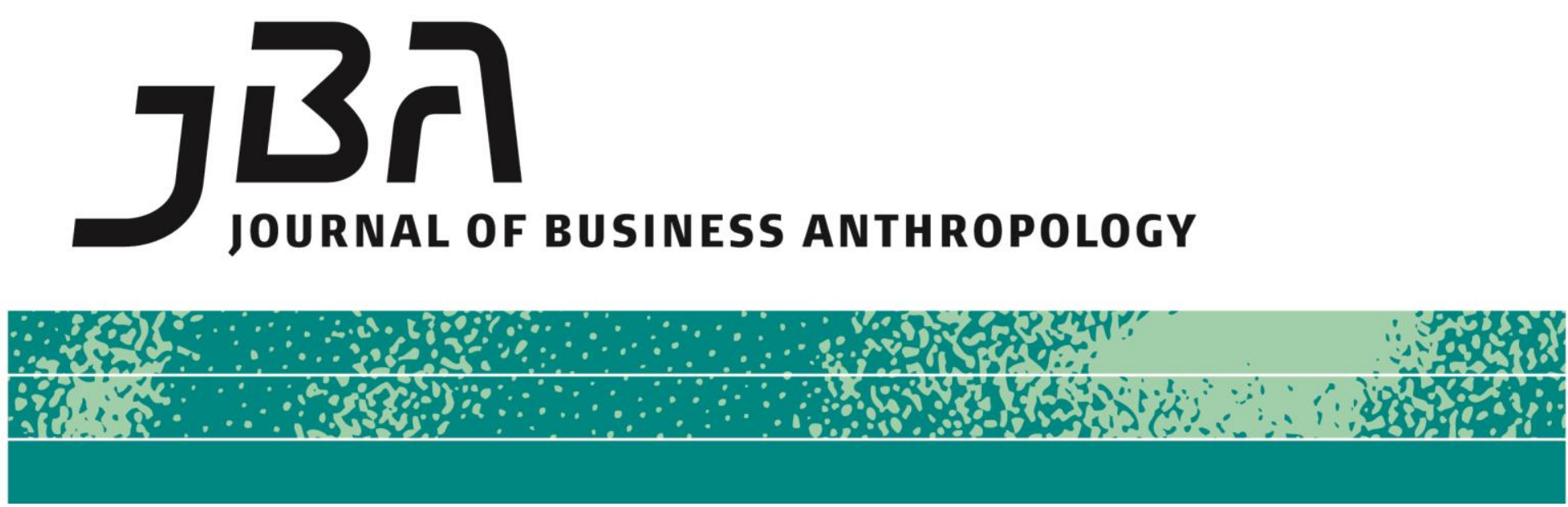

\title{
Anthropology and Power to the People?
}

\author{
Gillian Tett
}

A couple of decades ago, I took a career move that seemed somewhat odd: after I completed a PhD in social anthropology, I joined the Financial Times newspaper to report on business and economics. At the time, my colleagues were often baffled by the fact that I had studied anthropology, not economics. So were many of the business executives and policy makers I met.

That was no surprise. After all, in decades past, anthropologists and business leaders have often appeared to inhabit entirely different social tribes, in the Western world. The former were perceived to be devoted to studying exotic cultures and living fairly anti-establishment lives that were suspicious of money or capitalism; the latter were at the heart of the capitalist system and were usually far more interested in analyzing hard numbers than soft social issues.

To a hard-bitten economist, banker or policy maker, a subject such as anthropology was thus apt to seem rather "hippy," as one senior financier once remarked to me. Meanwhile, to many anthropologists, the world of Western business was not just morally dubious - but very boring compared to all the other issues and cultures that could be studied. Indeed, the gulf was so large that when I started my own PhD in anthropology at Cambridge University, in 1989, it never even occurred to me to study Western business: instead I headed off to Soviet Tajikistan, to study marriage rituals and ethnic identity in a remote mountain community; that fitted my idea (or prejudice) of what anthropology "should" be about. 
But these days, this great divide is finally - belatedly - crumbling. One reason is that the great financial crisis of 2008 showed financiers and policy makers that they need to study "soft" cultural issues, alongside their economic spreadsheets, if they want to understand how the world works. Another factor is that the leaders of giant multinationals are grappling with a host of new cross-cultural issues as they spread their wings around the world - and turning to anthropologists for help. A third issue is that the executives of tech companies are now increasingly interested in cultural issues, partly because they need to understand social patterns as they try to build new products in cyber space. And a fourth factor which is prompting new interest in the discipline comes, oddly enough, from the fast-evolving frontier of quantitative analysis: as computer scientists start to develop more sophisticated forms of data science, some business executives are starting to realise that they need cultural analysis when companies try to interpret Big Data.

At the same time, anthropologists themselves are increasingly realising that Western businesses can offer fertile territory to explore and widening their eyes beyond traditional fieldwork venues, or places such as Tajikistan. This is not simply because Western business environments can often be fascinating, but also because engaging with the corporate world can be a good way to promote anthropology ideas in the wider environment. And, of course, there is a very practical issue, too: if anthropologists can persuade more companies to hire them as consultants, it could provide a badly-needed source of jobs for graduates, at a time when many universities are cutting staff. This move does not come without compromises: when businesses use anthropologists as consultants or researchers, their goals are very different from academic work. But some anthropologists - as readers of the $J B A$ are aware - are finding ways to navigate these hurdles, particularly in the fast-growing technology world.

But if anthropologists do move into the world of business analysis or even just business journalism, like me - what exactly can they offer the non-academic world? The answer to that question is not always entirely obvious to outsiders, given that it has been widely presumed that what anthropologists really did was study exotic peoples, rituals and ideas, or collect artefacts. But the key point to understand about modern anthropology - as I often explain to non-anthropologists - is that what really defines the discipline is not any particular topic, but the method of enquiry. More specifically, to my mind there are at least five defining traits that shape how anthropologists look on the world - which can be profoundly valuable for others.

Firstly, anthropologists tend to take a "bottom up" view of the world, looking at life from grassroots, often by getting their feet dirty with participant observation. Secondly, they spend a great deal of time trying to join up the dots between different parts of peoples' lives. Those two 
points might sound terribly obvious (at least to anthropologists), but they are not in the business world; on the contrary, much of the analysis that policy makers, business executives, financiers or economists tend to use is diametrically opposed to these principles, since it relies on lofty views of life taken from 20,000 feet up in the air, with topics studied in separate silos. Using an anthropologist's perspective to study the world can thus yield insights that seem almost remarkable to corporate executives simply because anthropologists have talked to "real people" in a holistic way.

Thirdly, anthropologists tend to spend a fair amount of time looking at power structures, of the formal and informal sort. This is something that business executives often do not like doing, or not explicitly, since talking about power is something that is almost taboo. But precisely because of that, an anthropologist's perspective can be very useful. Fourthly, and leading out of that, anthropologists tend to analyze not just what people say, but what they fail to talk about as well. After all, it is a truism of anthropology that the way that an elite stays in power is by not merely controlling the means of production in an overt manner, but shaping the way that a society thinks, often in a manner that members of that elite themselves barely understand. And what matters in terms of shaping that world view are not merely the issues that are openly discussed, but also the ones which are ignored; social silences can be crucial for propping a system up.

Last, but not least, anthropologists also specialise in comparative analysis. One of the most powerful ways to see the contradictions and ambiguities in any cultural system or context is to look at another one first, and then compare; travel, be that of a mental or physical sort, tends to broaden the mind and offer fresh eyes and perspective on cultural patterns. Once again, that point appears entirely obvious to anyone steeped in anthropology; but it is not to non-anthropologists, or not to those in the business world.

This list of defining traits is certainly not exhaustive; on the contrary, many anthropologists will undoubtedly have others to suggest. But I have discovered these skills to be invaluable help in terms of business journalism. Taking a bottom-up, immersive approach to analyzing financial markets, that tries to join up the disparate pieces, explore what participants are not saying, and look at how this props up the people who are in power, has enabled me to see striking patterns that some of my colleagues have missed. But that principle can apply equally well to practitioners of business too. After all, the real beauty of anthropology is that it encourages people to ask the question: why? Why is the world arranged in this way? Why do we talk about some topics but not others? Why do groups coalesce in this manner, attach so much importance to particular objects, or think in a certain manner? Truly innovative people in business often ask these questions, instinctively. But 
established executives do not. And they sometimes bear heavy costs as a result. Many of the mistakes bankers made in the run up to the 2007 financial crash could have been avoided, if only more people had challenged their basic assumptions - and their mental blind spots - about the way that mortgages, say, were being handled.

In other words, the beauty of being an anthropologist in the business world today is that anthropologists can speak truth to power often by pointing out the most obvious, but undiscussed, things. "Power" - in the form of business leaders, policy makers or other executives - may not always want to hear that truth, far less to pay for consultants who offer such advice. But let us all hope that some do; not just for the sake of anthropologists, but business leaders and policy makers too.

Gillian Tett received a Ph.D. in Social Anthropology from the University of Cambridge in 1993, and joined The Financial Times as correspondent for, first, Europe and the former Soviet Union; then Tokyo; and then as the FT's Managing Editor in New York. She is currently Assistant Editor of The Financial Times and continues to write about markets and finance. Once described as "the most powerful woman in newspapers," she appears regularly on television programmes, as well as at other media and academic events. Her account of the financial crash in 2008, Fool's Gold, won the Spear's Book Award for the financial book of 2009. She may be reached at gillian.tett@ft.com 